\title{
La última poesía de Jorge Riechmann y los males de la postmodernidad
}

\author{
Jorge Riechmann's last poetry and the postmodern society's ills
}

Ambra Cimardi ambra.cimardi@unibg.it

Università degli Studi di Bergamo, Italia

Recepción: 12 Agosto 2019

Aprobación: 10 Mayo 2020

Publicación: 02 Noviembre 2020

Cita sugerida: Cimardi, A. (2020). La última poesía de Jorge Riechmann y los males de la postmodernidad. Olivar, 20(32), e086. https://doi.org/10.24215/18524478e086

\begin{abstract}
Resumen: En el presente trabajo analizamos los últimos dos poemarios de Jorge Riechmann: El común de los mortales (2011) y Poemas lisiados (2012) desde el punto de vista de las teorías sobre la postmodernidad y del compromiso ecológico.
\end{abstract}

Palabras clave: Jorge Riechmann, Compromiso ecológico, Postmodernidad.

\begin{abstract}
The purpose of this essay is to analyse Jorge Riechmann's last books, El común de los mortales (2011) and Poemas lisiados (2012), taking in consideration Postmodern theories and Ecocriticism.
\end{abstract}

Keywords: Jorge Riechmann, Ecocriticism, Postmodern theories.

\section{JoRge RiechmanN: UNA POESÍA CIRCULAR Y UNIVERSAL ${ }^{1}$}

Aunque los libros de Riechmann no se empezaron a publicar hasta la segunda mitad de la década de los ochenta, comienza ya su carrera como escritor en plena Transición. En 1977, la revista Cuadernos Literarios Sintesis propone uno de sus poemas y, en 1986, Luis Antonio de Villena, que anteriormente había formado parte del jurado de un certamen literario en el que Riechmann había participado, lo incluye en su conocida antología Postnovísimos (Montetes, 2001, en línea). El volumen contiene los textos de autores que, nacidos entre 1955 y 1962, toman parte activamente en el cambio estético (Iravedra Valea, 2016, pp. 63-66) que refleja la transición político-social vivida por España. El antólogo madrileño detecta una pluralidad de líneas plasmadas primariamente en dos caminos: el primero consiste en "el uso personalizado de la tradición clásica" y el segundo es el de "la que por mal nombre se ha denominado poesía del silencio, y que debiera llamarse, mejor, poesía minimalista, o tradición (aunque a veces desde ángulos mentales diversos) de la poesía pura” (Villena, 1986, p. 19). Al lado de Julia Castillo y de José Gutiérrez, seguidores de la línea metafísicominimalista, encontramos la obra neosurrealista de Blanca Andreu, la neorromántico-intimista de Miguel Mas y de Felipe Benítez Reyes (Lanz, 2007, pp. 136-137), los textos de Julio Llazamares, quien retoma aspectos de la tradición del versículo, "de la bárdica o chamánica” (Villena, 1986, pp. 26-27), los de Ángel Muñoz Pestime y de Leopoldo Alas, cercanos a la sensibilidad del rock (1986, pp. 27-28). Además, aparecen unos versos escritos por el propio Luis Antonio de Villena y publicados bajo seudónimo, los textos de Rafael Rosado y, en una línea realista, los de Luis García Montero y unos poemas inéditos de Jorge Riechmann, 
pertenecientes a la primera etapa del autor que está en una fase de experimentación continua en busca de su propia voz lírica. Las imágenes oníricas y surrealistas se alternan con representaciones nerudianas de una realidad impura y decadente, de dolor y muerte.

En 1987, el poeta abre su trayectoria creativa con Cántico de la erosión, que Alberto García Teresa (2013, p. 11) considera como el libro iniciador de la Poesía de la Conciencia Crítica. Con esta denominación, el investigador clasifica a autores que, a partir de las últimas décadas del siglo pasado, "sitúan el conflicto socioeconómico y político que atraviesa la actual coyuntura histórica en el centro y en el eje (implícita y explícitamente) de su creación poética, manifestándolo de una manera crítica” (2011, pp. 10-11). ${ }^{2}$ Describir la poética de Riechmann en pocas líneas resulta muy difícil, debido a la vastedad de los temas abarcados en sus poemarios (Iravedra Valea, 2018a, p. 250; Llorente, 2019, p. 586). Se trata de una trayectoria circular en la que el autor presenta una voz poética que lleva el lector a reflexionar sobre los males de la postmodernidad, mostrando cómo estos se multiplican con el paso del tiempo en lugar de desaparecer. Las cinco advertencias que encontramos en "Hipótesis de trabajo de Cántico de la erosión”, del primer libro, se desarrollan a lo largo de los poemarios posteriores: hace falta reflexionar sobre esta época injusta partiendo de los conceptos de erosión y ausencia; vivimos en una realidad en la que los seres no se preocupan por su futuro; como la lluvia ácida, el género humano se corroe a sí mismo y desgasta lo que encuentre; la complicidad con el sistema aniquila el planeta; el poder somete la masa a través de imposiciones sociales generando disparidades.

A lo largo de su trayectoria creativa, las imágenes oníricas, mitológicas y surrealistas de los libros iniciales (Martín López, 2014, pp. 11-12) dejan gradualmente espacio a lo que Luis Bagué Quílez define como "humanismo desnudo" (2006, p. 245), es decir, a representaciones cada vez más directas, herméticas y crudas de la decadencia del género humano. Como sugiere Francisco Javier Martín López, "se produce un paso de una poesía centrada en la expresión de un abismo interior a una poesía que aborda el horror que provoca la sociedad capitalista" (2014, p. 17), y esta inflexión se percibe a partir de El día que dejé de leer EL PAÍS (Bagué Quílez, 2006, p. 245). El yo lírico, que en muchos casos coincide con el autor empírico (Eco, 2005, pp. 10-32), ${ }^{3}$ se define por su voz combativa, por el carácter "feroz" y rabioso (Llorente, 2008, p. 586) y por cierta atención a los que sufren (Candau, 2000, p. 32). En su introducción a Futuralgia (2011a), libro que reúne la obra del poeta hasta La estación vacía (2000), Pedro Provencio (en Riechmann 201 1a, prefacio, párr. II) habla de "hiperconciencia" y hace hincapié en la dimensión universal de los versos de Riechmann, quien propone un análisis crítico "multidireccional y orientador de la acción". Se trata de un "estado de vigilia [...] que puede ser opuesto a la dominación imperial adoptada ya como normalidad evidente, justa y necesaria": los versos del poeta superan los límites humanos para llegar al conocimiento; en ellos, aparecen "tanto la actualidad más efímera, como la sabiduría más antigua” (Provencio, en Riechmann 2011a, prefacio, párr. II). El estudioso concluye afirmando que la obra del autor no se puede "encerrar entre fórmulas como poesía social, poesía testimonial e incluso política" (Provencio, en Riechmann 2011a, prefacio, párr. II): estas clasificaciones limitarían la interpretación de los versos del poeta, subrayando determinados aspectos y eclipsando otros. Antonio Candau (2000, pp. 27-31), Ángel Luis Prieto de Paula (2014, pp. 31-32) y Araceli Iravedra Valea (2018a, pp. 249-253) estudian la relación entre la poesía de Riechmann y la de los poetas comprometidos de la posguerra. El primer investigador se centra en la intertextualidad de la poesía del escritor madrileño en la que se detectan ecos de Ángel González, reconociendo tanto puntos de contacto como diferencias; los demás analizan la distancia entre Riechmann y Gabriel Celaya, no solo a nivel estilístico sino también de pensamiento. Para Riechmann, el poeta no es el superhéroe que sustituye a los que no pueden hablar, sino que crea las condiciones para que los más débiles encuentren un espacio donde expresarse (Prieto de Paula, 2014, p. 31; Iravedra Valea, 2018a, p. 250). Según García Teresa, los autores de la Poesía de la Conciencia Crítica siguen en la "búsqueda de cambio de conciencia del lector, pero sin otorgarle respuestas desde una sabiduría que ya posee el escritor y que revela al público, sino sencillamente manifestándole contradicciones y preguntas para que [...] el lector se replantee las relaciones de la sociedad" (2013, p. 46). Además, el estudioso considera el contexto histórico en el que esta corriente se desarrolla y subraya la diferencia con los períodos 
analizados por los movimientos anteriores $(2011$, p. 9). Riechmann vive los grandes cambios de las últimas décadas del siglo pasado; empieza a escribir durante la guerra fría, en Berlín ${ }^{4}$ observa las diferencias entre la realidad capitalista occidental y la comunista oriental, e, impotente, padece la afirmación de la sociedad líquida postmoderna (Bauman, 2004). Iravedra Valea (2018b, pp. 45-46) aclara que tanto la transición, caracterizada por los continuos cambios de gobierno, como "la caída del socialismo real en Europa" y el consiguiente ascenso del "capitalismo neoliberal" mendaz no condujeron a la "sociedad del bienestar", sino a la incertidumbre y alimentaron las nuevas tendencias poéticas del compromiso. La poesía de Riechmann se basa en la lucha contra el sistema tardo-capitalista que, dominado por los grandes grupos financieros, se caracteriza por el desarrollo tecnológico, la globalización y el consumismo; según el autor, estos generan una comunidad cada día más superficial, infantil, egoísta, antiecológica e individualista. Escribe Riechmann:

Cada día
un paso más
hacia la barbarie
ecológica
económica
política
cultural
emocional
social
anímica
cada día un pasito
y en los días malos
-no son pocos-
una buena zancada.
(2013, sp.)

Prieto de Paula (2014, p. 32) emplea el concepto de 'concentricidad' para describir la poesía del autor madrileño: el escritor proporciona al lector no solo una representación completa y fidedigna de la realidad española, sino también del mundo en su totalidad. Entre los versos de gran impacto sobre temáticas internacionales destacan los que describen la guerra y la opresión. "Contra el consuelo", de Cuaderno de Berlín (2011a, cap. 5, párr. II), está dedicado a Franz Fühmann, quien denunció en sus obras la brutalidad del fascismo; en "Leyendo a Ernesto Guevara" (2011a, cap. 17) de La estación vacía se rememora a las víctimas de la revolución cubana y, en "Campo abierto" (2011a, cap. 17), del mismo libro, a los difuntos en Auschwitz, tema recuperado en "Amasando pan y asando corazón" de Poesía desabrigada (2006, pp. 86-88). En Material móvil (2011a, cap. 7), se condenan las atrocidades de la guerra del Vietnam y en Poesía desabrigada se describe la crueldad de los conflictos en Ruanda (2006, pp. 89-91), en Irak (2006, pp. 100-101), y el horror de los ataques terroristas en Nueva York (2006, pp. 95-96) y en Madrid (2006, pp. 92-94). Otros poemas en que se manifiesta la universalidad de Riechmann son "Mujeres y montañas", de Material móvil (2011a, cap. 7), donde se abomina la violencia contra las mujeres; "Lapidación de matrimonio joven, 1993", de El día que dejé de leer EL PAÍS (2011a, cap. 16), en cuyas líneas se cuenta la historia de Noorjaham Begum, apedreada en Bangladesh por su segundo matrimonio y "Hand made in India” de El corte bajo la piel (2011a, cap. 14, párr. III), centrado en la disparidad entre los países ricos y la explotación infantil del tercer mundo. Según el autor, "no existen áreas de la realidad por donde no pudiera aventurarse la poesía" (en González Fuentes, 2005, p. 91); como subraya en "Realismo", para que lo que se cuenta acerca de la condición humana sea verídico y concreto, hace falta: "ESCRIBIR lo que somos / lo que no somos / lo que hubiéramos sido / lo que ya nunca seremos / lo que podríamos ser" (2011b, p. 54). Riechmann se sale de todo tipo de restricción formal (Iravedra Valea, 2018a, p. 252-253): solo hace falta comprometerse para desarrollar un mundo mejor. Como la realidad descrita, formada por múltiples entidades en continua conexión, los libros de Riechmann dialogan 
entre sí completándose recíprocamente. Considerando la coherencia de su trayectoria poética, en el presente artículo nos centraremos en los poemarios más representativos de la última etapa de la trayectoria del autor: El común de los mortales (2011b) y Poemas Lisiados que, publicado en 2012 y reimpreso en 2013, ${ }^{5}$ incluye versos escritos entre 2009 y 2011 . Se trata de dos libros que profundizan sobre las ideas dominantes del poeta y refuerzan su mensaje revolucionario.

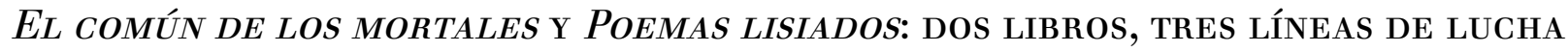

Concentrándose primariamente en tres temas entrelazados entre sí, en sus últimos dos libros Riechmann presenta una sociedad que está yendo hacia el apocalipsis y donde han cambiado los valores del pasado:

\author{
LA CONCIENCIA ${ }^{6}$ \\ ¿ES una enfermedad autoinmune? \\ LA INTELIGENCIA \\ ¿VA aprendiendo a no envenenarse a sí misma? \\ LA COMPASIÓN \\ ¿CABE que se sitúe mejor que un buñuelo dominical?
}

(Riechmann, 2011b, p. 75)

Para el autor, "los valores son creaciones históricas, son el producto de gente que busca ciertos objetivos, [...] son el sentido de la acción humana" (en Sánchez Medina, 2011, p. 62) y, por ende, es normal que muden. Como se observa en las tres preguntas, no siempre se trata de un cambio positivo: las metas fijadas en la época postmoderna no llevan a la pérdida de valores, sino a privilegiar lo que "desde cierta posición normativa son en realidad contravalores, antivalores o disvalores” (en Sánchez Medina, 2011, p. 62). En la contemporaneidad, la conciencia, la inteligencia y la compasión han sido relegadas al margen. En el primer caso, el individuo ya no reflexiona sobre sus acciones; sin darse cuenta, envenena con su ignorancia y soberbia tanto el entorno donde se halla como a sí mismo: la conciencia "se agota / en vacua lucidez / mientras la muerte va / ganando la partida" (2011b, p. 79). El tema de la precariedad humana se encuentra también en "Venimos a este mundo para aprender dos cosas" (2011b, p. 103), que hace hincapié en la incapacidad del sujeto de discernir entre lo que es fundamental en la vida y lo secundario. Demasiado concentrado en su subida en la escala social, el ser derrocha energías en futilidades, olvidándose del sentido primordial de la vida: venimos a este mundo para amar y, cumplida nuestra misión, fallecemos. Como afirma García Candeira (2014, p. 135), la denominación del poemario El común de los mortales (2011b) remite a que la voz poética reconoce los límites del género humano, entre los que prima la muerte. Esta toma de conciencia "aparece como fruto de una historia catastrófica, vivida como caída provocada por la lógica de la de 'hybris', que nos deja confinados a una condición esencialmente herida o lisiada, y de ahí el título del segundo poemario: los Poemas lisiados" (2014, p. 135). Caracterizada desde su origen por cierta inestabilidad interior, la humanidad ha desarrollado varias técnicas para compensar sus límites:

Un primer intento fue evadirnos en el más allá ultraterreno publicitado por todo un pool de divinidades tanto lugareñas como globalizadas. No salió bien. Hubo luego varios planes parciales de evasión a reservas culturales que prometían bastante: la posteridad, el panteón de hombres ilustres, enciclopedias, mausoleos, la gloria militar o literaria: no tuvieron mucho éxito. Invertimos enormes recursos en planes de evasión al cosmos, pero no llegamos más allá de la Luna 


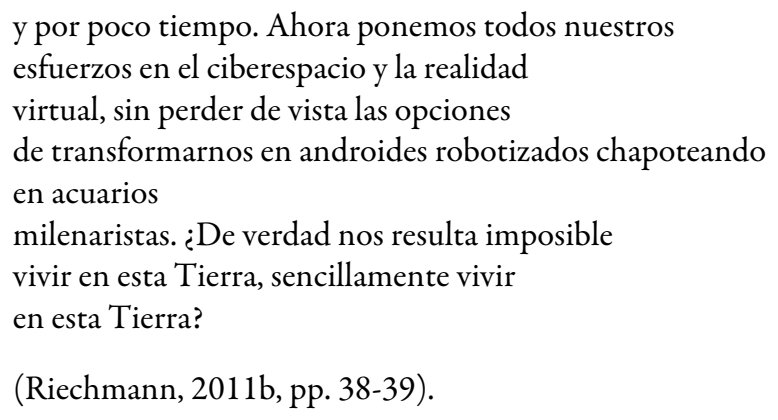

Con el paso de los siglos, la necesidad de buscar respuestas ha producido un progreso continuo, hasta llegar a la postmodernidad, en la que necesitamos huir del mundo enfermo que hemos generado (2011b, p. 211) - y de nosotros mismos (2011b, p. 38) - mediante el desarrollo tecnológico. Sin darnos cuenta, nos refugiamos en un universo irreal perfecto por ilusorio, que nos hace perder el contacto con el mundo físico a nuestro alrededor y con los demás, convirtiéndonos en autómatas incapaces de pensar y de actuar:

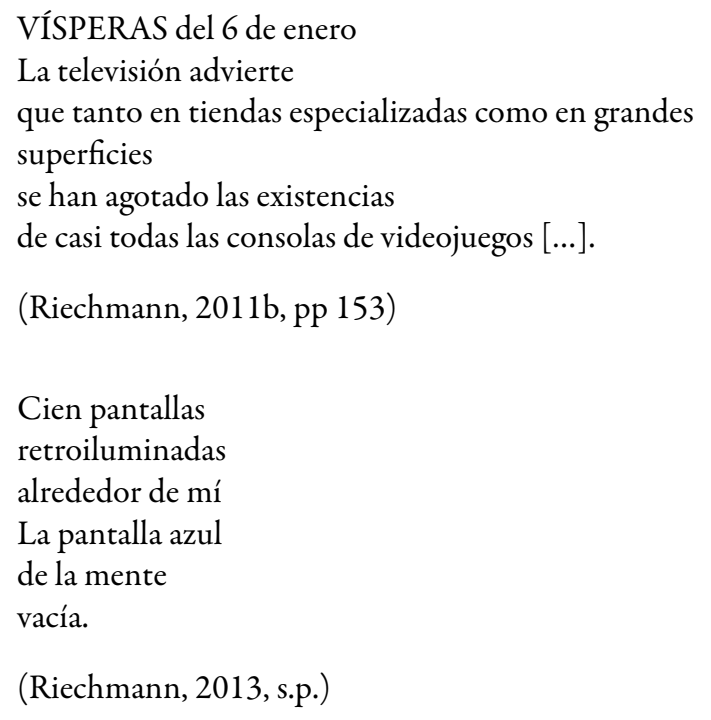

Los videojuegos, cada día más intuitivos, no requieren ningún compromiso y proponen realidades modificables, sometidas a nuestro control (Bauman, 2009, pp. 63-64). Con estas características, generan cierta dependencia que alimenta el sistema económico fundado en el consumismo y en la pérdida de las capacidades perceptivas. Las fiestas populares que agregaban la masa se han convertido en espacios virtuales (2011b, p. 199; 2013, s.p.) presentados no tanto como un problema sino como la solución para mejorar nuestras capacidades relacionales. Como subraya Bauman (2009, p. 64-66), las redes sociales rebosan de elementos que nos recuerdan la importancia de la socialización y que nos convencen de que internet es el mejor método para intensificar nuestras relaciones. En esta situación de "aislamiento" y "alienación del agregado masivo" (2011b, p. 154) perdemos nuestra inteligencia y compasión. Vivimos "Como los monos / tallados en madera en el santuario de Nikko: / el que se tapa los ojos / el que se tapa los oídos / el que se tapa la boca / los que con mimo cuidan / su no querer saber" (2011b, pp. 114-115). Nos dejamos someter por el poder que, como afirma Foucault, citado explícitamente en "llegar a ser sujeto" de Cuaderno de Berlín (2011a, cap. 5, párr. VI), convierte al individuo en sujeto, es decir en un ser "sometido a otro a través del control y la dependencia, y sujeto atado a su propia identidad por la conciencia o el conocimiento de sí mismo" (Foucault, 1988, p. 7). En "El hombre hueco" (2011b, p. 30) y en "Cuatro horas de televisión en promedio" (2013, sp.), Riechmann recupera el concepto de "servitude volontaire", propuesto en el siglo XVI por Étienne de La Boétie. En su ensayo innovador, el pensador francés analiza las dinámicas del poder que, radicalizado en la sociedad, se alimenta gracias a la masa, que se deja educar en la sumisión y acepta la falta de libertad 
sin reflexionar sobre la existencia de otra realidad posible (La Boétie, 1963, pp. 47-94). El sistema tirano se mantiene mediante la rutina, la ignorancia y la cobardía; les otorga fútiles diversiones a los seres humanos para distraerlos de su existencia y convertirlos en bestias sin capacidades críticas (La Boétie, 1963, pp. 69-77). Por un lado, el poder nos atrapa con el exceso de ofertas volubles, que estimulan continuamente nuestro interés (Bauman 2009, p. 33), por el otro, a través de los medios de comunicación, plasma nuestras normas de actuación y genera miedo y odio contra determinadas entidades. Estas estrategias permiten controlar la masa y limitar su descontento debido a las precarias condiciones socioeconómicas (Chomsky, 2004, pp. 61-62). Tanto en "Cuatro horas de televisión en promedio" (2013, s.p.), como en "El hombre hueco" (2011b, p. 30), Riechmann representa una imagen de desolación y deshumanización total. El primer poema describe la fuerza de la televisión que ciega a los individuos proporcionándoles una realidad sin contenidos; el segundo medita sobre la historia de la humanidad, caracterizada por seres secos con "rostros desvencijados" que solo pueden ofrecer al prójimo su "orina amarga": sustancia estéril, ácida y dañina. La deshumanización y la pérdida de la capacidad de pensamiento llevan a un mayor egoísmo, al individualismo y a la falta de compasión. En "Qué hacer" (2011b, pp. 93-95), hay una crítica feroz contra la marginalización de los ancianos en nuestra comunidad:

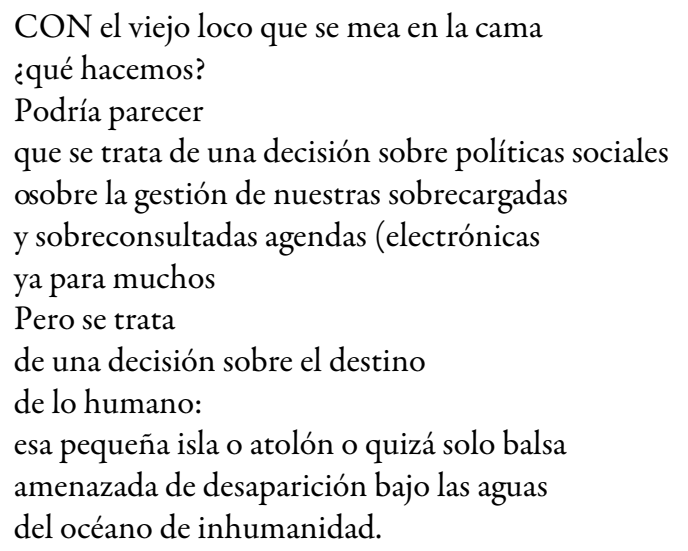

(Riechmann, 2011b, p. 93)

Sin empatía ni compasión, consideramos a las personas mayores como objetos sin valor, un compromiso más en nuestras agendas siempre llenas, un asunto económico y social que encerramos en centros privados, es decir, en lugares heterotópicos (Foucault, 1984, en línea) ${ }^{7}$ que los alejan de nuestra cotidianidad. En el orden frenético preestablecido, los jóvenes no tienen tiempo ni para profundizar en su pasado, hablando con los ancianos, ni para pensar que, siguiendo así, se hallarán en condiciones peores: serán viejos enfermos abandonados a sí mismos en una sociedad cada día más cruel. Si la poesía de Riechmann es un canto de desesperación, es también un grito de lucha. El autor termina la composición con una invitación al lector para que reconozca la situación de degrado a la que hemos llegado y escribe: "Nos dicen / que no se puede hacer otra cosa / que dejaros morir / y no es cierto. / Se os puede / acompañar en ese viaje terrible / como cada uno de nosotros querrá / ser acompañado" (2011b, p. 95). La falta de solidaridad se expresa de otra manera en "dos encuentros" (2011b, p. 83), donde un perro desnutrido y golpeado, víctima de la brutalidad humana, bebe y come lo que el yo lírico le ofrece, y luego se escapa. Riechmann presenta la ferocidad intrínseca en quienes arremeten contra los desprotegidos simplemente para gozar de su violencia y vuelve a la incapacidad de identificarse en los demás del ser humano. La voz poética condena a los que cumplen un gesto de caridad solo para recibir algo a cambio: las personas no se contentan con que el animal aterrorizado haya confiado en ellas. La imagen del perro tullido como símbolo de falta de compasión aparece también en "Cachorrito redrojo", donde la voz poética pregunta: “¿acordamos / entonces que la vida / es la arquitectura / de las interrupciones / la intermitencia de la piedad / y la entre crujida / de los reencuentros?” (2013, s.p.). La 
misma violencia se observa también en “¿Nadie cuida a nadie?” (2011b, p. 37), donde unos niños despedazan luciérnagas. El género humano no solo ha perdido la capacidad de relacionarse entre sí, sino también con los seres de otras especies y con la naturaleza que lo rodea.

\section{Otra línea de LUCHA: EL ACTIVISMo Ecológico De RiechmanN}

Las tres líneas temáticas presentadas se entrelazan con la lucha ecológica, en la que el autor siempre ha intervenido activamente. A lo largo de su trayectoria creativa, se intensifica el intento de concienciar al lector sobre los problemas medioambientales vigentes, desde una perspectiva inclusiva del género humano en el hábitat donde se encuentra. ${ }^{8}$ Según Riechmann, uno de los mayores déficits de nuestra colectividad es la escasa participación en actividades sociales: vivimos en comunidades "que son formalmente democráticas; pero en las que, sin una implicación activa de los ciudadanos en los asuntos de todos, no hay democracia posible. Democracia es participación en lo común, o no es nada" (en Ferrari y Genovese, 2006, p. 232). El equilibrio enfermo y paradójico establecido, en el que somos víctimas y asesinos a la vez, se subraya en "Ecocidio" (2011b, pp. 129-136). La primera parte se centra en el fenómeno del deshielo acelerado en el paso del Noroeste, entre Groenlandia y Canadá. Reproduciendo el lenguaje periodístico, la voz poética critica los medios informativos que disminuyen los problemas ecológicos poniendo al lado del artículo sobre el calentamiento global otro texto que elogia los éxitos de la industria española en el mercado internacional:

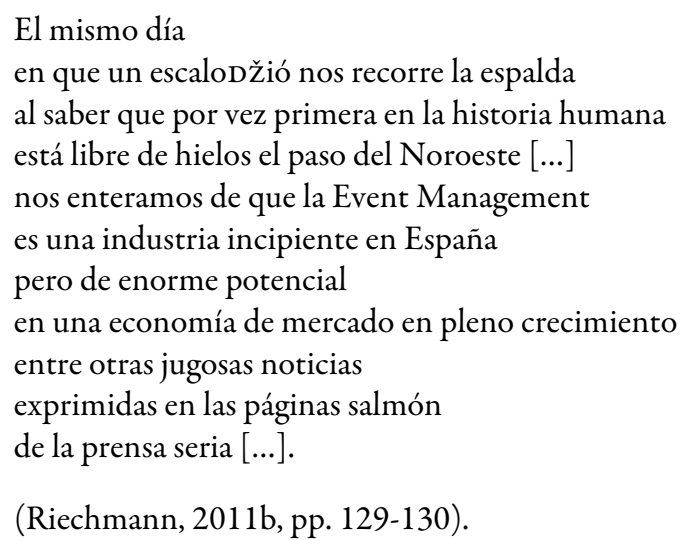

La estrategia de acercar la sensación de escalofrío al concepto de calentamiento del planeta y el juego de palabras de los versos “jugosas noticias / exprimidas en las páginas salmón” expresan una amarga ironía que remarca la falta de seriedad en la prensa y, más en general, en el sistema vigente. En la tercera parte de "Ecocidio", el autor recupera las palabras de Margaret Thatcher, quien declara "que un hombre de más de treinta años / que viaje en autobús -no en avión o en automóvil- / ha de considerarse fracasado” (2011b, p. 131). Como se asevera en el quinto apartado (2011b, p. 132), el concepto de 'sostenibilidad' todavía no se ha arraigado ni en nuestra cultura ni en la manera de pensar de los políticos, quienes deberían ser un ejemplo para la colectividad. Las ciudades no están diseñadas para los peatones (2011b, p. 132) y, después de muchos siglos de urbanización,9 las estrategias de las metrópolis para interaccionar positivamente con el mundo natural son demasiado débiles: los automóviles proliferan en las calles (2013, s.p.). Según Riechmann, la situación se debe a la incompatibilidad de la sostenibilidad con un sistema como el nuestro, "que necesita vender cantidades siempre crecientes de mercancías -sin límite- para subsistir" (2012, p. 61). De acuerdo con esta posición, Noam Chomsky (2004, pp. 82-84) considera únicamente económicas las razones por las que los gobiernos no incentivan las alternativas a conducir en las metrópolis. El pensador subraya como los medios de transporte colectivos, que en muchos casos han sido privatizados, son caros e ineficientes y las carreteras permanecen llenas de agujeros: gastamos dinero tanto en la gasolina como en la manutención de los coches. Además, las enfermedades debidas a la contaminación del aire aumentan y pagamos cada día más la sanidad pública. En la poesía de Riechmann, las ciudades son el símbolo del orden 
voraz capitalista-industrial: se contraponen a la armonía de la naturaleza que mantiene activos los sentidos de quienes van contracorriente. Tanto en "Apenas lluvia" (2011b, p. 17), como en "Contra la indiferencia" (2011b, p. 28), encontramos un fuerte contacto entre la naturaleza y el yo lírico que, durante su contemplación, medita sobre el sentido de la vida. "La condición humana IV" (2011b, p. 104) remite a la idea gongorina, retomada por Antonio de Guevara, de menosprecio de corte y alabanza de aldea (Beverley, en Góngora 2016, pp. 37-42): según la voz poética, en una realidad muerta, los hombres construyen autopistas y fastfoods solo para sentirse vivos, aunque, este tipo de reificación "Es su desgracia y la nuestra / Les falta por completo la intuición / del frescor de la fuente / en no existir" (Riechmann, 2011b: 104). En la sexta parte de "Ecocidio" (2011b, pp. 132-133) hay una reflexión sobre la gran cantidad de material plástico contaminante empleado y, en los últimos cuatro apartados (2011b, pp. 134-136), el yo lírico condena la arrogancia, la estupidez y la hipocresía de nuestra sociedad. $\mathrm{Si}$, por un lado, los poderosos maximizan su bienestar aumentando las industrias sin pensar en las consecuencias (2011b, pp. 134-135), por el otro, organizan eventos ecológicos que sirven únicamente para reforzar su imagen pública y no para concienciar la masa (2011b, pp. 135-136). Según el autor, las nuevas técnicas productivas sostenibles se desarrollan con la misma lógica empresarial; en sus versos, Riechmann no critica la tecnología, sino cómo el género humano la usa de forma equivocada:

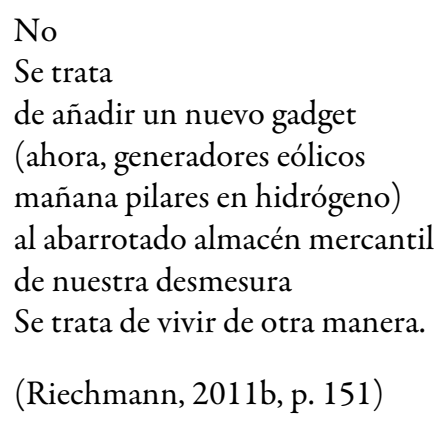

Riechmann hace hincapié en la incapacidad de cambiar nuestras costumbres que depende de las estrategias adoptadas por el sistema para evitar su subversión: favorece la abolición del pensamiento crítico y contrasta a quienes lo desarrollan. Los partidarios del productivismo consideran a quienes hablan de ecocidio como "gente exaltada / poco de fiar entregada a emocionales / trifulcas que oscilan / entre la inanidad y la intemperancia / más parecidos / a aquellas clásicas histéricas del XIX (...)” (2011b, p. 147). Como se lee en "Catastrofismo II" (2011b, p. 149) y en "Catastrofismo III" (2011, p. 150), los detentores del poder encubren los desastres medioambientales que producen y alimentan el egoísmo de la masa que sacia sus necesidades a costa del ambiente: "Lo preocupante no es -nos advierten- / la violencia de la publicidad / ni el terrorismo del dinero / Lo que debe angustiarnos / es la terrible dictadura ecologista en ciernes / que pretende limitar la libertad de subirnos al avión / caiga quien caiga". No nos percatamos de que la Tierra sufre y seguimos destruyendo el planeta; restos de aviones (2013, s.p.) y de barcos (2011b, pp. 127-128) se quedan abandonados en los océanos contaminando el hábitat marino, los peces que comemos están llenos de mercurio (2013, s.p.) y la basura se apodera del entero universo: “¿Qué hacen los pedazos de basura / de satélites atómicos girando / sobre nuestras cabezas a quinientos kilómetros / de altura?” (2013, s.p.). Arrogantes, no solo hemos organizado nuestra especie en clases sociales, sino que también hemos sometido a categorías todos los elementos que componen lo creado: en nuestro orden, los animales y el ambiente están por debajo de nosotros y, por ende, tenemos el derecho a colonizarlos. Riechmann detecta una actitud de superioridad del ser humano frente a la naturaleza (2011b, p. 193) y de sumisión al mundo high-tech creado por él mismo (2011b, p. 217). Nos hemos alejado de la primera para acercarnos al segundo, sin privilegiar lo que nos podría salvar, es decir, que los dos colaboren. En la realidad del glamour donde los 
problemas se convierten en obviedades (2011b, p. 160), vivimos en el autoengaño de la eternidad; la imagen clásica de la planta que pierde sus hojas para representar el tempus fugit se sustituye con la de un árbol de plástico que parece permanecer siempre verde aunque se trata de un arbusto "cada vez más amargo caduco y polvoriento" (2011b, p.101)

\section{Conclusiones}

Mediante la representación de la desolación humana y de las injusticias que se han generado en la época postmoderna, Riechmann conciencia a su lector sobre lo que define como una "crisis sistémica [...] amenaza de colapso ecosocial" (Riechmann, 2012, p. 175). Formando parte de la misma colectividad descrita, el receptor se reconoce en sus versos y medita sobre los temas analizados. Como afirma García Teresa refiriéndose a los miembros de la Poesía de la Conciencia Crítica: "La búsqueda de lo colectivo de estos poetas también constituye un ejercicio consciente dentro de un planteamiento general de resistencia, que tiene como objetivo la transformación social” (2011, p. 44). Para el autor, la poesía despierta en su público el espíritu crítico perdido en un mundo enfermo que necesita cada día más diagnósticos (2011b, p. 211-212). El poeta lucha contra el sistema capitalista sin dejarse englobar: para mejorar el mundo, solo necesita su ingenio y un "bloc de notas de 1,95 euros" (2011b, p. 49). Si para los potentados la lengua es un conjunto de estrategias para obtener favores, beneficios, dinero, para los literatos la palabra es vida y verdad (2011b, p. 50; pp. 52-53). Más que nunca, necesitamos versos reales que devuelvan la humanidad a los sujetos: la poesía confiere sentido a nuestras existencias combatiendo contra las incertidumbres, es fuente de calor y afecto que contrastan la violencia de la cotidianidad, nos aleja de los males del mundo cada día más presentes (2011b, p. 44; pp. 49-50). En un periodo histórico donde "falta lenguaje / para decir / el horror que viene" (2013, s.p.), el escritor tiene que encontrar el modo más fidedigno e impactante para representar la situación actual. Como señala García Candeira (2014, pp. 133-137), para el autor, la poesía no tiene que oponerse al sistema solo a nivel de contenido, sino también estilístico; según la investigadora, "Riechmann compone una propuesta de resistencia radical: la lógica del capital puede combatirse mediante la lógica del don y, de modo íntimamente relacionado, a través de una intensa práctica de despojamiento" (2014, p. 133). En la época de los excesos hace falta desprenderse de todo para "ganar [...] y recibir el céntuplo" (2013, s.p.), es decir, para volver a la conciencia, a la inteligencia y a la compasión, que determinan nuestra humanidad. García Candeira (2014, p. 136) demuestra que para el escritor madrileño hace falta una poesía sincera, directa, descalza (2013, s.p.), aunque colmada de significado (2011b, p. 197). La palabra poética es una forma de investigación que nos mejora: "Se escribe / para aprender a escribir / para aprender a vivir / para aprender a aprender / y uno no deja nunca / de ser un aprendiz / jinete de buidos animales / más sabios y expectantes y libres que sí mismo" (Riechmann, 2011b, pp. 41-42). En su representación de la desolación contemporánea, el autor no pierde la esperanza que aparece cada vez más explícita a lo largo de los poemas. Como afirma Candau (2000, p. 27), no se trata de una ilusión ingenua, sino de una voluntad razonada; en su poesía, el escritor no desea evadirse de la realidad, sino transformarla. La salvación de este mundo infame depende de nosotros mismos y de nuestras acciones, como escribe el poeta: "para ver / la puerta abierta / has de pensar que la puerta / puede abrirse" (2011b, pp. 209-210). Riechmann condena el cinismo y el pesimismo histórico: los escépticos han olvidado las potencialidades del ser humano y han perdido su voluntad de vivir decidiendo incorporarse al sistema (2011b, pp. 167-168); en un mundo a la deriva, es más simple, más rápido y menos decepcionante expresar negatividad, rendirse y esperar pasivamente el final de nuestra existencia (2011b, pp. 172; 233). A pesar de esta tendencia dominante, para Riechmann siempre hay una salida: la poesía y el amor son dos razones para existir y luchar, le devuelven al ser su libertad (2011b, p. 251). A lo largo de su obra y, sobre todo en la segunda parte de Poemas lisiados (2013), "tratar de amar" (2017, s.p.), el sentimiento amoroso es una modalidad de salvación que ayuda a los valientes que no han perdido la capacidad de sentir emociones para que soporten la realidad en la que se hallan, antes de morir. El amor, en todas sus formas, acerca a las 
personas, detiene la deshumanización y la pérdida de los vínculos sociales: nos mantiene vivos (2011b, p. 57; p. 61; p. 65; 2013, sp.). Escribe Riechmann: "para caer hacia arriba / no hay otra vía que la de amar / muy mucho" (2011b, p. 66).

\section{REFERENCIAS}

Bagué Quílez, L. (2006). Poesía en pie de paz: modos del compromiso hacia el tercer milenio. Valencia: Pre-Textos.

Bauman, Z. (2004). Modernidad líquida (Rosenberg, M., y Arrambide Squirru, J. trad.). Buenos Aires: Fondo de Cultura Económica.

Bauman, Z. (2009). Capitalismo parassitario (Cupellaro, M., y Galimberti, F. trad. de las entrevistas). Bari: Editori Laterza.

Candau, A. (2000). Jorge Riechmann y la metamorfosis de la experiencia. España contemporánea: Revista de literatura $y$ cultura, 13(1), 7-36.

Chomsky, N. (2004). Il bene comune (Barsamian, D. ed., y Domenichini, E. trad.). Casale Monferrato: Piemme.

Correyero, I. (1998). Feroces. Radicales, marginales y heterodoxos en la última poesía española. Barcelona: DVD.

Ferrari, M. B., y Genovese, G. A. (julio 2006). Jorge Riechmann: «todo puede ser salvado» (entrevista a Jorge Riechmann). Alpha, 22, 225-234.

Eco, U. (2005). Sei passeggiate nei boschi narrativi. Milano: Bompiani.

Falcón, E. (2009). Once poetas críticos en la poesía española reciente. Versión corregida para el MLRS. Recuperado a partir de http://www.nodo50.org/mlrs

Foucault, M. (1988 [1982]). El sujeto y el poder. Revista Mexicana de Sociologia, 50(3), 3-20 (Iturbe, C. de trad.). Recuperado a partir de http://links.jstor.org/sici?sici=01882503\%28198807\%2F09\%2950\%3A3\%3C3\%3AE SYEP\%3E2.0.CO\%3B2-A

Foucault, M. (octubre, 1984). Des espaces autres. Hétérotopies. Architecture, Mouvement, Continuité, 5, 46-49. Recuperado a partir de https://foucault.info/documents/heterotopia/foucault.heteroTopia.fr/.

García Candeira, M. (enero 2014). Poesía en crisis en el panorama español: despojamiento y lucha en la trayectoria última de Jorge Riechmann. Hispanófila, 170, 129-148.

García Teresa, A. (2013). Poesía de la Conciencia Crítica (1987-2011). Madrid: Tierra de nadie.

García Teresa, A. (2015). Disidentes: antología de poetas críticos españoles (1990-2014). Madrid: La Oveja Roja.

González Fuentes, J. A. (2005). El pulso de la bruma (artículos). Santander: Centro de Estudios Montan\#eses.

Góngora, L. de (2016) Soledades (1613). Ed. de J. Beverley. Madrid: Cátedra.

Iravera Valea, A. (2016). Hacia la democracia. La nueva poesía (1968-2000). Madrid: Visor Libros / Centro para la Edición de los Clásicos Españoles.

Iravedra Valea, A. (2018a). «¿La poesía es un arma de futuro cargada?» Los compromisos poéticos posmodernos o el canon bajo sospecha. Estudios Filológicos, 61, 243-263.

Iravedra Valea, A. (2018b). El compromiso después del compromiso. Poesía, democracia y globalización (1980-2005) (Extracto). Kamchatka. Revista de análisis cultural, 11, 39-55.

La Boétie, E. de (1963) Discours de la servitude volontaire (1576). Ed. de M. Rat. París: Colin.

Lanz, J. J. (2007). La poesía durante la Transición y la generación de la democracia. Madrid: Devenir Ensayo.

Llorente, M. (2008). Poemas críticos en la España contemporánea. Hispania, 91(3), 579-589.

Martín López, F. J. (2014). Poesía y poética de la conciencia de Jorge Riechmann: aproximación a sus primeras obras. Revista Vozes dos Vales: Publicaçôes Acadêmicas, 6 (Año III), 1-22.

Montetes, N. (2001). Entrevista a Jorge Riechmann. The Barcelona Review: revista internacional de narrativa breve contemporanea, 9. Recuperado a partir de http://www.barcelonareview.com/25/s_ent_jr.htm.

Mosley, S. (2013). Storia globale dell'ambiente (Neri Serneri, S. ed., y Petrucciani, T. trad.). Bologna: Il Mulino. 
Ortega, A. (1994). La prueba del nueve (antología poética). Madrid: Cátedra.

Prieto De Paula, A. L. (2014). La poesía concéntrica de Jorge Riechmann. Ínsula, 811-812, 31-34.

Riechmann, J. (2006). Poesia desabrigada. Santa Cruz de Tenerife / Las Palmas de Gran Canaria: Ediciones Idea.

Riechmann, J. (2011a). Futuralgia (versión Kindle). Isbn digital: 978-84-8359-281-6.

Riechmann, J. (2011b). El común de los mortales. Barcelona: Tusquets.

Riechmann, J. (2012). El socialismo puede llegar sólo en bicicleta. Madrid: Catarata.

Riechmann, J. (2013). Poemas lisiados (2012). Torrejón de Ardoz, España: La Oveja Roja.

Sánchez Medina, A. (mayo 2011). Entrevista Jorge Riechmann. Leer, p. 62. Recuperado a partir de https://www.acad emia.edu/18629690/Entrevista_Jorge_Riechmann._mayo_2012._N._222.

Villena, L. A. de. (1986). Postnovisimos. Madrid: Visor.

\section{Notas}

1 Este artículo se halla vinculado al Proyecto de Investigación del Plan Estatal «Poéticas de la Transición (1973-1982)» financiado por: FEDER/Ministerio de Ciencia, Innovación y Universidades- Agencia Estatal de Investigación/ FFI2017-84759-P.

2 Los volúmenes de García Teresa, Poesía de la Conciencia Critica (1987-2011) (2013) y Disidentes: antología de poetas críticos españoles(1990-2014) (2015), completan el trabajo de las antologías anteriores, entre otras: La prueba del nueve (1994) de Antonio Ortega, donde se recogen a autores que, con voces líricas diferentes, "invitan a una reflexión crítica sobre la realidad, sin concesiones a la versión socialmente concordada de la misma, pero tampoco a su versión literariamente armonizada" (1994, p. 10); Feroces. Radicales, marginales y heterodoxos en la última poesía española (1998) de Isla Correyero, que confirma el desarrollo de una nueva "actitud vital comprometida" (1998, p. 8); Oncepoetas criticos en la poesía española reciente (2007) de Enrique Falcón, donde se reproducen algunos de los textos más representativos de la "literatura de voluntad crítica y pulso resistente en tiempos [...] de macdonalizada pacificación e innegable injusticia social” (2007, p. 8).

3 La superposición entre el autor empírico, es decir Jorge Riechmann, y la voz poética que nos guía en nuestra interpretación se hace evidente en Poemas lisiados (2013), donde aparece la caligrafía del autor: el volumen incluye poemas que no han sido transcritos por ordenador y "está maquetado sobre la disposición de un cuaderno suyo, comprado en la antigua Alemania del Este” (García Candeira, 2014, p. 141).

4 En las páginas de presentación de Cuaderno de Berlín el autor escribe: "La primera estadía en Berlín se prolongó desde septiembre de 1986 hasta junio de 1987. Madrid, Berlín: dos polos de electricidad humana cuya notoria diferencia de potencial puede cargar de energía cualquier vida dispuesta a intentar la aventura de la lucidez sin resignación [...] Huelga recalcar que no he escrito un libro sobre Berlín, sino uno desde esta ciudad; quise que Cuaderno de Berlín fuese no un álbum de impresiones sino la organización de una experiencia (que se deja dispuesta para que pueda acaso servir a otros). [...]" (2011a, cap. 5, páginas de presentación).

5 Citaremos de la segunda edición de Poemas Lisiados, publicada en 2013, en la que no aparecen los números de páginas.

6 Las mayúsculas son del autor.

7 Foucault define las heterotópicas como lugares efectivos "qui ont la curieuse propriété d'être en rapport avec tous les autres emplacements, mais sur un mode tel qu'ils suspendent, neutralisent ou inversent l'ensemble des rapports qui se trouvent, par eux, désignés, reflétés ou réfléchis" (1984, en línea). Su presencia varía a lo largo del tiempo, tienen un funcionamiento definido en la sociedad, pueden contener lugares incompatibles entre sí, en algunos casos presentan una ruptura con el tiempo tradicional y están aisladas con un sistema propio y selectivo de apertura y cierre (1984, en línea).

8 Se trata de una perspectiva actualmente poco común. Escribe Riechmann: "el séptimo de los Objetivos de Desarrollo del Milenio [...] reza así: 'Garantizar la sostenibilidad del medio ambiente’. Ya esta forma nos remite al notable embrollo [...] que rodea la cuestión del desarrollo sostenible: pues no resulta difícil pensar que induce a un doble error. En primer lugar, apunta hacia un 'medio ambiente' circundante y distinto de nosotros, y así apuntala una errónea idea de separación entre naturaleza y sociedad. En segundo lugar, por supuesto, no es la sostenibilidad de los sistemas naturales lo que hay que garantizar: es la sostenibilidad de los hoy muy insostenibles sistemas humanos" (2012, p. 57).

9 Stephen Mosely (2013, pp. 129-169), profundiza la compleja relación entre el mundo urbano y el ambiente a lo largo de los siglos. Partiendo de las primeras formas de civilización hasta llegar a nuestros días, el estudioso ilustra atinadamente las problemáticas surgidas en los diferentes períodos históricos, centrándose en las múltiples fases de concienciación del género humano que, con sus acciones, modifica el hábitat a nivel global. 